\title{
LEARNING A LANGUAGE THROUGH GAMING: A MINECRAFT GAME DESIGN FOR NEGOTIATION OF MEANING AND CO-CONSTRUCTION OF KNOWLEDGE
}

\author{
Joeun Baek ${ }^{1}$ and Hyekyeong Park ${ }^{2}$ \\ ${ }^{1}$ Boise State university, Department of Literacy, Language and Culture, 1910 University Drive, Boise ID USA 83735 \\ ${ }^{2}$ Sancheong Middle School, Sancheong Gun, Gyeongnam, South Korea 52203
}

\begin{abstract}
The purpose of this study is to design a Minecraft game where players can learn a language by negotiating meanings and constructing knowledge together with other players. In order to achieve this purpose, related theories are explored and an instructional design theory was adopted to provide a background for a game building. After the game was designed, it was implemented to test its feasibility. A further suggestion for re-design of the game as a next step was made.
\end{abstract}

\section{KEYWORDS}

Minecraft, Learning Language through Games, Negotiation of Meaning, Knowledge Construction

\section{INTRODUCTION}

This study aims to design a Minecraft game where players can communicate to play, negotiate meanings during play, and construct knowledge together with other players. In order to achieve the goal of the study, learning theories related with role playing and research on Minecraft use in the classrooms are explored. In addition, the instructional design theory of Gagné is reviewed as a basis for building the game. After the game is designed, it was implemented to test its feasibility.

\section{LEARNING BY PLAYING ROLES AND MINECRAFT}

\subsection{Learning by Playing Roles and Minecraft}

Even though role playing has been actively utilized in language learning class, the application of massively multiplayer online role-playing games (MMORPGs) is still controversial since many people many people doubt how influential these games are on learning. Role playing in language learning basically has learners taking a role of a particular person or character and acting out as if they are the real person or character. Liu and Ding (2009) insist the positive effects of role-play by arguing that the technique can animate the learning atmosphere, provoke interests to learn and make the language acquisition impressive. According to Dorathy and Mahalakshmi (2011), there are a variety of reasons that role-paying should be implemented in language classes. Not only does role-play help learners deal with real-life situations and daily expressions, but also it encourages learners to work together in order to understand each other. In addition, role-play can be reorganized based on student' interest or need, which enhances learner' responsibility in learning and motivation. Through MMORPGs, which contain all the features of role-play, learners are expected to participate in language learning in a meaningful way. Moreover, when considering the requirements of successful completion of MMORPGs, we can easily find their similarity with the conditions of successful 
language learning. Peterson (2010) suggests features of MMORPGs and their potential advantages to second language learning.

The use of Minecraft in classroom environments has been explored in a variety of studies. Researchers have suggested ways to integrate the game into curriculums, offered insight into some benefits and drawbacks of doing so, and proposed possible paths of further application (Callaghan, 2016; Kuhn, 2017; Mail, 2015; Petrov, 2014; Steinbeiß, 2017) The majority of this research lends evidence to the theory that Minecraft is a highly beneficial tool for education. Thus, in this study, the researchers aim to design a Minecraft game to help and facilitate players learning a language through negotiating meanings and co-constructing knowledge.

\subsection{Minecraft in the Classrooms and Teachers' Role}

Some teachers have used Minecraft in a variety of subjects and areas of education already. Players were instructed to create in Minecraft and keep journals of math and writing (Petrov, 2014). Other teachers observed social skill development, and one teacher used Minecraft to help players make real-life objects with 3D printing (Petrov, 2014). Educators who have integrated Minecraft in their lessons have found superb results. Teachers noticed that students were more motivated to do work and developed their communicative and social skills (Petrov, 2014). Another key point to mention about Minecraft is that students were engaged in unexpected ways. Aside from increased rates of assignment completion, for example, students who normally did not actively take leading roles in class were able to act as leaders within the game (Hulstrand, 2015). One main factor in ensuring the helpfulness of Minecraft is peer-to-peer collaboration, as more experienced gamers can use their skills to enable a smoother integration of the game with all students (Hewett, 2016). However, the varying levels of student experience- which, understandably, may be a point of concern - did not detract from learning. Players who are beginners at the game, with some instruction, could follow along with the lesson relatively well (Callaghan, 2016).

Not only are teachers paramount in enabling an effective use of the game in learning, they are also crucial in getting such a program started in their classrooms. For maximum success, teachers should be fully supportive of the idea, and their teaching styles should be compatible with a student-centered approach (Petrov, 2014). Teachers should also be familiar with the game and with knowledge of how social interactions and spaces within the game function. However, many teachers are reluctant to use Minecraft in their curriculum, and part of this may stem from the gap between students' and teachers' video game literacies (Kuhn, 2017).

Minecraft is seen to be an effective tool in varying circumstances for learning. It upholds principles crucial to effective learning by providing motivation, improving social and communication skills, and encouraging critical and creative thinking. Further research on how Minecraft benefits players, as well as on how to make it more suitable to teachers as well as learners, is thus promising.

\section{DESIGN REFLECTED BY AN INSTRUCTIONAL THEORY}

How the activities of gaming in Minecraft could be arranged for language learning is a question of identifying, selecting, arranging, and sequencing the learning experience for players. Gagné, Briggs, and Wager (1992) provide a good framework for designing learning. They developed a framework of nine general events that should take place during learning. This process is called Gagné's Nine Events of Instruction.

\section{DESIGNED VILLAGE FOR LANGUAGE LEARNING}

Based on the reviews on theories related to language learning and design of educational games, a Minecraft game was designed as below presented. 


\subsection{Getting Started with Landmarks}

In the Landmarks, players are expected to learn the information regarding some landmarks in the world. While playing the games, they will visit several famous landmarks in the world. By looking around the landmarks, they will read and collect some pieces of information related to each landmark. In the perspectives of language learning, players should be able to negotiate the meanings of unfamiliar words they encounter and construct new knowledge in groups.

In the game, the negotiation of meaning and co-construction of knowledge occurs as follows: While looking around the Eiffel Tower and playing the game, players are asked to keep in mind the information related to the Eiffel Tower for the quizzes later. Then, players will delegate who memorizes which information. This encourages players to communicate and interact with each other more actively, and by having a role, players will be more responsible to the task or the game.

Although each student has their own role to memorize a piece of information, players will help each other when they find some challenging expressions such as 'be named after' and ' 81 -storey building' because they need to collaborate to complete the whole game. To understand the meaning of difficult words, players will take a guess and share their ideas with other players. By doing so, players understand the meaning of the challenging words, and they naturally co-construct the knowledge regarding the Eiffel Tower. While negotiating the meaning of incomprehensible words such as 'emperor' and 'plunder', players will use their own background knowledge or take a guess. If they cannot figure out the meaning, they can ask for help to a teacher or a teacher's avatar in the game. In this case, the teacher decides whether the challenging words are key words students must understand. If so, the teacher gives hints so that players can figure out the meaning of the words by themselves. By doing so, players can figure out the words' meaning, which is the result of negotiation of meaning and co-construction of knowledge.

\subsection{Having Fun in the Amusement Park}

In the Amusement Park, players are expected to complete the given quests in an amusement park and zoo. While playing the game, players will experience some typical situations they are likely to have when they visit a real amusement park or a zoo. Players in the beginning of the game will buy tickets for the ride. Also, they will order food in a cafeteria, and look around the zoo for certain animals. Since all these situations are related to their actual lives, players will be more motivated to play the games and learn new expressions in English.

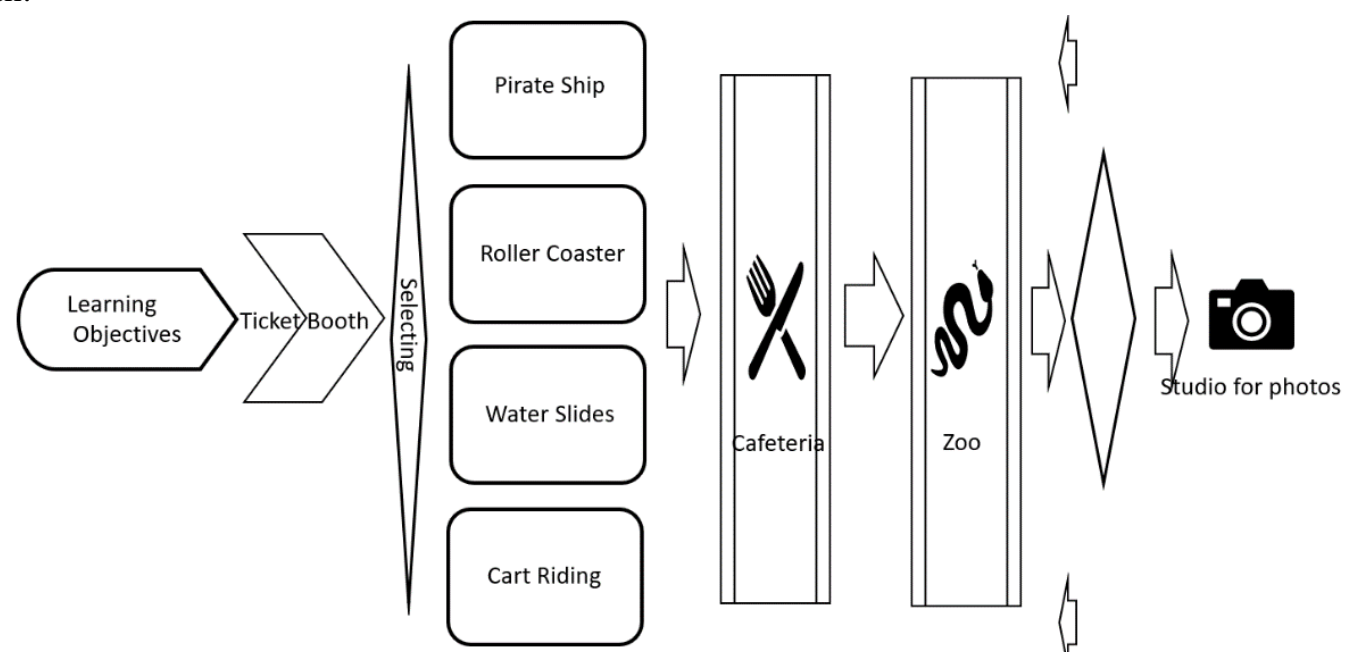

Figure 1. Activity Flow in Amusement Park

Players will be able to negotiate meanings and co-construct new knowledge in groups. In the game, players will experience a variety of meaning negotiation and knowledge co-construction situations. For instance, players will discuss with others to choose a ride. They also have chances to read the safety instruction before going on rides, so when they do not understand some difficult words, they will negotiate the meaning by sharing each other's background knowledge. Through the process of complete quests, players 
will come to learn which expressions to use in each situation resulting in co-construction of knowledge about the related situations and the appropriate expressions in English.

In the theme, numerous events are implemented for players to have meaning negotiation and knowledge co-construction. Specifically, after being told about today's game goals, players move to a ticket box to buy the tickets for rides. In the ticket booth, players will have a conversation with an NPC or a teacher's avatar regarding 'buying tickets.' The conversation will be about the cost, discount, coupon, and so on. When players find some unfamiliar words or expressions, they negotiate the meaning of the incomprehensible words with other players or the teacher's avatar. Through this, players come to understand the situation and learn new expressions related the situation. This leads to co-construction of knowledge related to 'buying tickets in the public places' such as amusement park and museums. At a cafeteria for lunch, players will discuss what to eat after reading the menu. Discussing the menu, players will learn some new words related to food and they will have active communication. While ordering food, players are asked to talk about detail preference regarding the food, such as 'What kinds of sauce do you like for your French fries?" When players need more explanation about the food, they can ask to the clerk, and this naturally provokes negotiation of meaning. Through this series of activities, players will be aware of what to say in English when ordering food, which indicates construction of knowledge regarding 'ordering food in a restaurant.'

\subsection{Attending a Party at a Friend's house}

In the Amusement Park, players should be able to complete the quests required to visit a friend's house. In the beginning of the game, players are invited to a house party hosted by a friend. On the way to the friend's house, players stop by a DVD shop and supermarket. To complete the requests, players need to use appropriate game strategies and have conversations in English with other characters.

In this game, players are exposed to various situations which have them negotiate meaning and co-construct knowledge. For instance, once players enter the supermarket, they walk around to find the items they need to buy. Some of the ingredients such as 'beetroot' and 'salmon' are unfamiliar for them. To figure out the meaning of the words, they negotiate the meaning with each other or they can get help from pictures. In addition, players can choose one item they want to buy for the party. To determine the item, players share their ideas, and this leads active interaction and authentic communication. Through this whole process, players will negotiate meaning of incomprehensible words and co-construct of knowledge regarding 'the name of some ingredient' or 'expressions related to grocery shopping'.

\subsection{Designing a Share House}

As the activities in 'Designing a Share House' mostly depend on players' preference and creativity, they provide a variety of chances for negotiation of meanings and co-construction of knowledge. In detail, players in the beginning enter a basement room to figure out what materials they can use to decorate the house. There, players will help each other understand what each item is and how they can be used to decorate the house. During this process, players naturally have conversations regarding the items and when a student does not understand the exact usage of the item, other players can explain more simply by repeating the key words or using easier words. After figuring out the items to use, players move to the living room. Then players share their ideas on how to decorate the house. For example, players assign which part each student will decorate and what type of items or materials they will use for the decoration. Players might have some misunderstanding due to some player's lack of language competency. In this case, players will help each other to solve the misunderstanding or miscommunication by giving feedback or using simpler vocabularies, all of which includes negotiation of meaning. Since players come to learn the name of items and how to use them for house decoration in addition to new English expressions, they will co-construct the knowledge relating to the given topic.

\section{IMPLEMENTATION AS A PILOT TEST}

After the game was designed, two technology teachers at elementary schools played the game. They were told about the game in advance and introduced how it was developed. After review, they reported that the intended features could be easily found in the designed Minecraft games. 
Above all, players in the games are encouraged to interact with each other through chat rooms for a variety of purposes. In the theme 'Designing a Share House', players could have discussion time regarding how to decorate their shared house. In the discussion, players could assign a role to each other to decorate the whole house and talk about how to achieve the given quests, such as which material they are using and what furniture they have chosen. This interaction provides learners not only with a chance to communicate in the target language but also the opportunity for exchanging linguistic feedback or negotiating meanings when they do not understand each other. Moreover, every theme of the Minecraft games has clear goals for players to complete. In the case of 'The Landmarks in the World', players are asked to look around some landmarks in the world such as Machu Picchu and the Sphinx, and take quizzes related to the landmarks. As the level of quizzes is slightly difficult for one player to handle alone, players are naturally led to collaborate with each other by assigning a role and helping others to understand unfamiliar words or phrases in games. Lastly, like typical RPGs, players in Minecraft also could have their own avatars. When playing with avatars, learners are less afraid of making mistakes since the avatar is not identified to their actual ego in reality (Chin, Oppezzo, \& Schwartz, 2009). Consequently, this reduced inhibition makes players participate in the learning process more actively, leading to the development of their language skills. Two technology teachers also reported that the game should have more conditionals and loops so that players can repeat their game at any place and time.

\section{CONCLUSIONS AND NEXT STEPS}

The designed game is expected to be a useful tool for learning languages by negotiating meanings and co-constructing knowledge while playing the game. However, as the pilot test shows it has several recommendations to revise towards a more beneficial tool for language learning. Researchers will start to get more data when more students play the game. In addition, the game will be applied for students to learn a language to see if it is effective and what has to be done in terms of its design in order to enhance players' language learning.

\section{REFERENCES}

Callaghan, N., 2016. Investigating the role of Minecraft in educational learning environments. Educational Media International, Vol. 53, No. 4, pp. 1-17. doi:10.1080/09523987.2016.1254877

Chin, D. B., Oppezzo, M. A., \& Schwartz, D. L., 2009. Teachable Agents and the Protégé Effect: Increasing the Effort Towards Learning. Journal of Science Education and Technology, Vol. 18, No. 4, pp. 334-352.

Dorathy, A. A, \& Mahalakshmi, S. N., 2011. Second Language Acquisition through Task-based Approach - Role-play in English Language Teaching. English for Specific Purposes World, Vol. 33, No. 1, pp. 1-7

Gagné, R. M., Briggs, L. J., \& Wager, W. W., 1992. Principles of instructional design (4th ed.). Fort Worth, TX: Harcourt Brace Jovanovich College Publishers.

Hewett, K. J. E., 2016. The Minecraft project: Predictors for academic success and 21 st century skills gamers are learning through video game experiences (Doctoral dissertation). Texas A\&M University-Corpus Christi, College Station, USA.

Hultstrand, A., 2015. Minecraft in the Math classroom. Methods, Benefits, and Difficulties of Minecraft Integration (Senior honors thesis). Liberty University, Lynchurg, USA. Retrieved from https://digitalcommons.liberty.edu/cgi/viewcontent.cgi? article=1591\&context=honors

Kuhn, J., \& Stevens, V., 2017. Participatory culture as professional development: Preparing teachers to use Minecraft in the classroom. TESOL Journal, Vol. 8, No. 4, pp. 753-767. https://doi.org/10.1002/tesj.359

Liu, F., \& Ding, Y., 2009. Role-play in English Language Teaching. Asian Social Science, Vol. 5, No. 10. pp. 140-143.

Peterson, M., 2010. Massively multiplayer online role-playing games as arenas for second language learning, Computer Assisted Language Learning, Vol. 23, No. 5, pp. 429-439. DOI: 10.1080/09588221.2010.520673

Petrov, A., 2014. Using Minecraft in education: A qualitative study on benefits and challenges of game-based education, Unpublished master's thesis, University of Toronto, Ontario, Canada.

Steinbeiß, G. H., 2017. Minecraft as a Learning and Teaching Tool - Designing integrated Game Experiences for formal and informal Learning Activities. Unpublished master's thesis, University of Oulu, Oulu, Finland. 